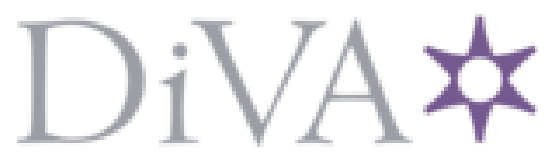

http://www.diva-portal.org

This is the published version of a paper published in International Journal of Technology Intelligence and Planning (IJTIP).

Citation for the original published paper (version of record):

Nybacka, M., Ericson, Å., Larsson, T. (2010)

Prospective service innovation in automotive testing - beyond distributed technology.

International Journal of Technology Intelligence and Planning (IJTIP), 6(1): 14-31

http://dx.doi.org/10.1504/IJTIP.2010.033921

Access to the published version may require subscription.

N.B. When citing this work, cite the original published paper.

Permanent link to this version:

http://urn.kb.se/resolve?urn=urn:nbn:se:bth-11251 


\title{
Prospective service innovation in automotive testing: beyond distributed technology
}

\author{
Mikael Nybacka*, Åsa Ericson \\ and Tobias C. Larsson
}

Division of Functional Product Development, Luleå University of Technology,

SE-971 87, Luleå, Sweden

Fax: +46920491074

E-mail: mikael.nybacka@1tu.se

E-mail: asa.ericson@1tu.se

E-mail: tobias.c.larsson@ltu.se

Website: www.ltu.se/tfm/fpd

${ }^{*}$ Corresponding author

\begin{abstract}
In this paper, a Remote Technology Management (RTM) solution is presented for the purpose of elaborating on how it can bring about opportunities for new innovative services in the automotive winter testing industry. The idea is to visualise how service providers can go from a product focus to a future where they take an active role as an expertise in the testing activities. Based on the premise that technologies like RTM can become a basis for novel services, the activities at a proving ground are described from three actors' point of view and discussed in terms of service innovation.
\end{abstract}

Keywords: automotive testing; winter testing; PSS; product-service systems; service innovation; remote technologies.

Reference to this paper should be made as follows: Nybacka, M., Ericson, $\AA$. and Larsson, T.C. (2010) 'Prospective service innovation in automotive testing: beyond distributed technology', Int. J. Technology Intelligence and Planning,

Biographical notes: Mikael Nybacka is an Assistant Professor and commenced his $\mathrm{PhD}$ studies in June 2005 with a research project within the Centre for Automotive Systems Technologies and Testing. In his work he studies the testing methods of automotive winter testing to highlight how software for vehicle dynamic simulation and supporting technologies can be used to enhance testing activities, collaboration and procedure.

Åsa Ericson is an Assistant Professor and received her PhD Degree in FPD in December 2007. She has an educational background in social informatics and systems sciences. Her areas of interest are in human centred design, customer information and communication in the early phases of engineering design.

Tobias C. Larsson is the Head of the Division of Functional Product Development at the Luleå University of Technology, Sweden. Firmly acquainted with simulation driven design, his research interest concerns knowledge based methods and tools. 


\section{Introduction: more than just a car}

Today, the design and development of cars is a highly collaborative effort between several actors. For example, while the Volvo XC90 is manufactured in Sweden, it sources most of its parts and components from supply-chain partners dispersed all over the world (Larsson, 2005). Cars are becoming complex, not only in terms of collaboration, but also in terms of interacting systems, such as Electronic Stability Program (ESP), Anti-lock Braking System (ABS), Traction Control System (TCS), Active Rollover Protection (ARP); i.e., several different control systems that have to interact to perform well during the drive. This has resulted in an increase in electronics, including software in cars (Grimm, 2003). Going from the past until today, the first implemented devices fulfilled single dedicated tasks, e.g., electronic injection, while cars nowadays are equipped with embedded systems linked in multiple networks taking care of more advanced tasks, e.g., automatic alert of an emergency service via the airbag control (Grimm, 2003). The multiple networks allow the design of functions that can combine several systems as, for example, vehicle dynamics and navigation information, but it also brings in additional efforts to make it work well. The S-Class of Mercedes-Benz contains more than 50 controllers, more than 600,000 lines of code, 3 different bus systems and around 150 messages and 600 signals (Grimm, 2003). The interaction between the systems is commonly addressed in the later stages of product development (Krüger et al., 2004), while $30 \%$ of severe malfunctions in the car are caused by faulty systems and software (Schäuffele and Zurawaka, 2005).

Makin all these parts and systems fit together is complex as it is. Having the goal of developing a safe, high quality, comfortable, easy to use car with low emissions and low impact on the environment adds to the complexity. To assure meeting the goals, it is necessary to perform validation verification and evaluation of the car and the parts continuously at proving grounds and in simulated real-life and harsh environment. Efficient testing activities are vital to make sure that the components and the systems in the car are functioning as intended.

At first, the testing activities at a proving ground seem to mainly incorporate technical aspects where the prototype cars and its components are in focus. But the services related to car testing are important to ensure a professional test. Service providers are people who supply the proving ground and the subsequent services. At a proving ground, the tracks to run the test on are rather obvious, but beside them there are also needs for administrative services, accommodation, logistics, access to local test drivers for endurance tests, mechanics, and information and communication technologies, and so on. On the test site, people from the car manufacturing companies and component companies are the customers, but the service providers have to work closely with them during the tests. Accordingly, there are many 'pieces' that have to come together to perform a test, e.g., people, technology, cars and facilities.

All the actors' joint efforts on the test site are aimed at making the actual tests as good as possible. In general, the testing activities are performed to evaluate one component at the time, this takes time. In automotive winter testing the weather conditions play an important role, too. For instance, the temperature and the ice on the tracks have to be the same to gain useful results of a repeated test. Further, how the driver was driving during the first test have to be as similar as possible in a repeated test, unless the intention is to evaluate the car systems based on different driving styles. 
In spite of this, the lack of standardised testing sequences is a concern in the automotive industry.

Overall, in the area of engineered products, like cars, the support of computer tools and software is important, testing activities are no exception. Engineers from car manufacturing firms, engineers from component firms and the service providers test managers have expertise in using computer support tools and software. Technologies that are used are, for example, sensors, equipment to log data and software to help visualise data. But, also, the actors have to cope with interpretation of measurements/results, updates of embedded software, since reporting and fixing computer problems and software are part of the work. On the winter test site, all actors that have an engineer background have skills in using technology support, though the support are firmly assigned to role specific expertise. In this way, each test has to be well planned and coordinated, and, in the perfect test, the technical equipment interacts as intended.

In a best-case scenario, technologies have the potential to transcend knowledge specific areas and empower people to gain expertise in new fields. Product-Service Systems (PSS) is a movement in manufacturing industry, which is partly based on the idea of changing how engineering tools and software are applied in early development (Sandberg et al., 2005). PSS incorporates a shift in business logics for how manufacturing firms develop, sell and maintain their products, i.e., as services instead of products. Framed by PSS, this paper embarks from the premise that remote technologies can become a basis for service innovation in automotive winter testing. Thus, the purpose is to present a Remote Test Management (RTM) technology and exemplify how it can open up a window of service innovation in the testing industry.

The RTM technology is a result of a research project, where some parts already are implemented in winter testing. In general, remote monitoring in fleet management activities has been identified as having a potential to bring about new businesses (Carlson, 2006). In particular, the benefits of implementing a remote solution have to first be understood to gain from the investment (Carlson, 2006). The efforts in this paper aspire to contribute to that.

Typically, research within the area of the automotive industry and test industry and in the area of automotive winter testing has received limited attention from academia. To our knowledge, studies from a service innovation point of view are limited, especially from the service providers' perspective. Therefore, the theoretical basis for this study includes the idea of PSS. This is a frame that is leaning on a service perspective as a trigger for changes in product development. Yet, it also provides a wider view on service development, as is the case for the testing activities.

\section{Approach for this study}

For the research project, the testing activities at 10 proving grounds in northern Sweden have been observed during 4 seasons of winter testing activities, from 2005 to 2008 . The winter season lasts from November until March. The observations are regarded as data collected in informal meetings; thus, they might be better described as participatory observations. On an overall level, the research approach in the project has followed Participatory and Appreciative Action and Reflection (Ghaye et al., 2008).

For this paper, 9 interviews, 2 surveys and 2 workshops have been performed to collect data from the actors at 5 of the proving grounds included in the whole research 
project. These proving grounds were chosen on the basis of access to respondents. The interviews were semi-structured, that is a topic was settled beforehand and focused on during the interviews, though the respondents could freely decide what to relate to the chosen topic. In this way, the expressions become grounded in the respondents' way of talking and thinking. Each interview lasted between $1 \mathrm{~h}$ and $1.5 \mathrm{~h}$. The interviews were audio recorded, from which excerpts have been transcribed.

One survey composed of 38 questions and the other 13 questions. In total, all 51 questions were designed to generate qualitative data. In this study, the 'open' and qualitative answers in the surveys have been used. These qualitative parts are designed to allow the respondents to formulate their answers in their own words and expressions. In total, 13 persons responded to the surveys.

The first workshop was conducted in August 2008 with one participant from the service providers, representatives from two local companies, a consultant from the automotive test industry, and people from academia (related to the overall research project). The focus in this workshop was "the future of vehicle testing". The second workshop was conducted in April 2009; besides people from winter testing and the research project, people from a related research project also participated in this workshop. The focus of this workshop was "new services around the intelligent inland road". The first workshop lasted one day (lunch to lunch), and the second lasted for $3 \mathrm{~h}$. A total of 24 people participated, the main part were actors from winter testing. Personal notes, pictures and the internal reports from these workshops have served as data for this study.

People from three main actors have participated in the interviews, surveys and the workshop. These actors are:

- Car manufacturers, called Original Equipment Manufacturer, OEM.

These people are responsible for the development of the car as a whole.

- Main part suppliers, called Tier 1 suppliers. These people are responsible for the development of sub-systems like ABS, ESC, TCS, but also 4WD power trains.

- Test entrepreneurs, called service providers. These people are those who own and develop the proving ground facilities and subsequent services.

Some of the tools and software that are used in the testing activities are developed in-house by the automotive industry and software companies develop some. Besides the fact that two representatives from a software development company participated in the workshops, the study presented here does not emphasise this point of view. The study is limited to a service providers' actor view and is based on a PSS perspective.

\section{Product-Service Systems: a new business model}

Product-Service Systems (PSS) is a concept that has received attention in the research field of product development the recent decade and it still does. Interpreting the term literally, PSS is an integration of engineered things (products) and services. Roughly, PSS is about developing functionality and providing this as a service, meaning that the business models and the development processes have to change to fit such a situation. Though the term PSS as such is not established in the industry (Williams, 2007) or in the business world (Charter et al., 2006), there are some aspects that characterise the movement in both strands. Examples of common interests are provision of added 
value to customers and collaboration between companies in development phases. Such characteristics goes under different brands in industry, but are gathered here under the umbrella term PSS.

The concept of PSS conveys an approach in opposite to the contemporary way to

- develop a product

- handing over the ownership to the customer, i.e., selling the thing

- providing maintenance and spare parts on an aftermarket.

For a PSS solution, the business partners, for example suppliers and sub-contractors, move their positions in the value chain closer to the developing company to provide for the design of the contracted functionality or service. In that way, this can be seen as the formation of an extended enterprise where the actors work jointly to develop the PSS.

Perspectives of PSS entail typically:

- Product-oriented services: Sale of the product with additional services (Williams, 2007) (for example insurances and prolonged guarantees provided by car brand).

- Use-oriented services: Product central, but owned by service providers and made available in different forms (Williams, 2007) (for example car leasing or rental).

- Result-oriented services: The partners agrees on a desired outcome but not specifying the involved product (Williams, 2007) (for example car pooling where the desired outcome is transportation).

Accordingly, for a car manufacturer, a PSS strategy changes the view from producing a car to understanding the use of cars to develop functionality that fulfils the users' needs and goals. This extension in business logic is what can be briefly explained as a shift towards a service perspective for manufacturing firms. As a consequence, PSS can be seen as an opportunity to radically change the development activities to take additional aspects into consideration early on. For example, how we use cars for transportation highlights ecological aspects in early development of cars (Mont, 2002; Carlson, 2006).

In the context of PSS also the way services are developed seems to be affected. Commonly, in product development, services are seen as aftermarket activities. This indicates that the physical artefacts are central and that services are seen as complementary to the core solution (Normann, 2001). From a service perspective, it can be argued that it is the other way around, i.e., that a service is first developed and existing products are incorporated to support the service. Services can be described as activities or processes where the provider and the customer are contributing to the outcome, i.e., services are to some extent produced and consumed at the same time (Grönroos, 2000). Therefore, the terms production and delivery does not fit well in a service context (Grönroos, 2000). In general, services are produced and used just as needed and at a time and place of the customers' choosing (Edvardsson et al., 2000). A tradition within service research is a focus on consumers (Bovik, 2004), while the terms consumer and consumption is not used by manufacturing firms in a business-to-business environment. Also, the description of customers as an abstract group called 'the market' has received some criticism. In development, argues the critic, this view makes customers the recipients at the end of a chain of activities of transforming raw materials to products and gradually adding some value (Normann, 2001). Regardless of applying a service or a product perspective, at the heart of PSS is the integration of both services and products 
in early development processes. And, also, the integration of two totally different logics is found as challenging. However, based on the idea that services are co-produced in relationships, networks and through interaction (Gummesson, 2002), the core idea of closer collaboration between manufacturers, suppliers and customers makes it interesting to explore service innovation in winter testing.

\section{The proving grounds for winter testing}

The geographical place for the proving ground matters, a prerequisite for winter testing is access to coldness. The natural assets - cold weather - and large inhabited areas are a backbone in the business concept for services in automotive winter testing. ${ }^{1}$ The testing can be performed in realistic settings, but cold chambers are also provided. Sparsely populated areas $(0.89 \text { persons per square kilometre })^{2}$ are appreciated by the customers at the proving grounds. It is valuable to run tests in secrecy especially since the testing activities involve prototype cars. Also, the sparsely populated areas in northern Sweden offers many kilometres of nearly deserted public roads of different kinds for different kinds of tests. Further, the ice tracks on natural lakes, as shown in Figure 1 are considered as a determining reason why the proving grounds in northern Sweden is found useful for the automotive industry. The proving grounds also provide different kinds of special tracks for the testing activities; like split- $\mu$, hill climb and urban track (these are shown in Figure 2). The special tracks are important since they simulate realistic circumstances, bumpy roads etcetera, but also they are used to 'push the limit' when testing cars.

Figure 1 Natural ice tracks on lakes

CBosch with permission (see online version for colours)

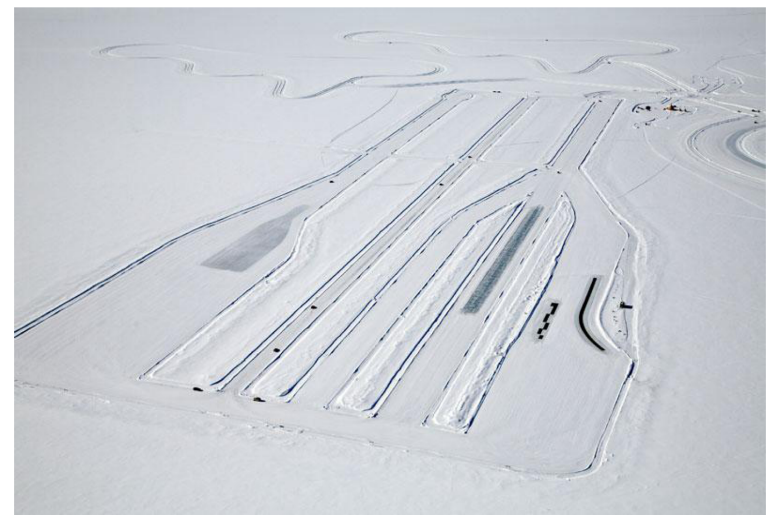

The testing industry is vital for northern Sweden, the largest service provider have a yearly turnover of 21 million EURO. Further, during the Swedish Automotive Testing Seminar, 2009, the following facts of the Arjeplog test industry were given for the season 07/08:

- 58,800 man-day's of testing were performed

- 2100 vehicles were tested

- 2800 engineers at the same day lived in Arjeplog. 
There is also a group called the Swedish Proving Ground Association. This group consists of 10 service providers that have established a collaborative network for winter testing. The proving grounds play an important role for social and economical growth in the inland parts of northern Sweden, since it also means employment within; for example, hotels, travel agencies and tourism companies. The proving grounds in northern Sweden are exposed to competition mainly from Finland and North America for winter tests. There are a number of OEMs that have firmly established their testing activities to Sweden, due to, as our respondents express it, to the fact that they need "guaranteed cold weather, new snow and big temperature variations", within the relatively short time period for testing activities. Another reason for choosing northern Sweden is expressed by the respondents as the large number of other automotive companies that have their tests situated in the area. So, clients attract new clients, and, accordingly good customer relationships are vital. Further, a crucial reason for this region popularity is the people's language skills, which makes the services on site and off without problems of miscommunication.

Figure 2 Split- $\mu$, hill climb and urban tracks CBosch with permission (see online version for colours)

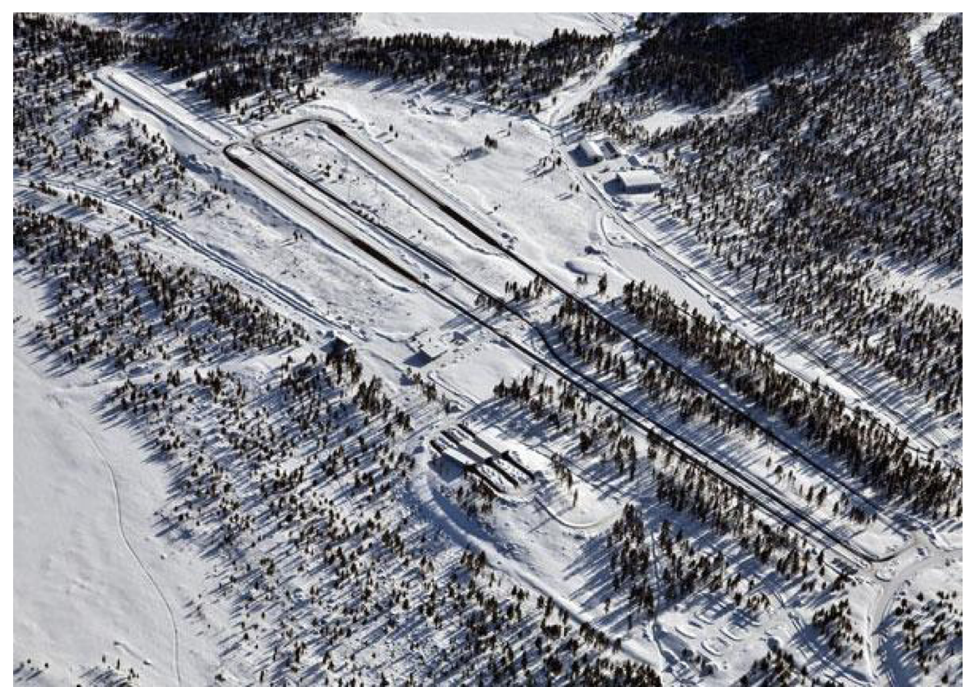

From the service providers' perspective, the short winter testing season is found to be troublesome. They have to uphold the work of their employees, and seek to prolong the season to also encompass summer test. Extending the test tracks and building new facilities is activities that uphold the work for their employees. But, it seems like the competition from other countries for summer tests becomes harder than for winter tests, thus requiring a different approach. For the winter test, the service providers are aware of their competitive strength and the important role they play in automotive industry. One of the service providers explained: "You do not send 100 cars from Korea to northern Sweden just for fun". The service providers constantly seek to improve their services, though they find it challenging to set the direction. However, they have identified some interesting areas, namely, continue to develop improved test methods, increase the quality of work (ISO9001 certification), more specialised persons, 
more people with engineering competences, closer testing projects with customers and supporting technologies for test activities and track preparation.

\section{The winter testing activities}

Tests of various kinds are performed at the proving grounds. To give some examples, the following are commonly done:

- Climate control: The vehicle is cooled down in a cold chamber to a minimum of $-40^{\circ} \mathrm{C}$ and then data are logged from a cold start until the temperature is stable. An example of measures is the time for the climate control to reach the adjusted temperature, and one assessment example is the test driver's perception of the airflow and if it feels like a draught.

- Vehicle handling: The most comprehensive tests for evaluating the vehicle with different manoeuvres. ESP, ABS and TCS are typical systems that concern vehicle handling. In these tests, special tracks are important to replicate a variety of real situations and to 'push the limit' in the tests. ESP safety tests include, e.g., ice tracks - lane change, fishhook turns, sine with dwell (Proposed FMVSS No. 126, 2006), etc. and also land based tracks - split- $\mu$, checker board, etc.

- Emission testing: Running the vehicle from a cold start to measure how the emissions are reduced when the engine increases in temperature. These tests also have to be done according to regulations.

- Durability testing: Long-distance driving for the purpose of collecting mileage on the car to, for example, study what happens to components in terms of changes in behaviour and properties. These tests are also conducted during summer time usually on $70-80 \%$ gravel roads.

- $\quad$ Noise Vibration and Harshness (NVH): These tests are performed on urban tracks to simulate in-city driving and on tracks and roads with different roughness. Driving in an urban environment means that the car has to be comfortable and not make strange noises when managing sharp corners, garage entrances and exits, etc.

- $\quad$ Tyre test: Tyre manufacturers evaluate different types of winter tyres, along with car magazines and other organisations that run tyre tests to provide for comparative studies to the public.

- Presentations: The service providers often present new systems like ABS, ESP, TCS systems at the proving grounds. These demonstrations are performed between different companies, but mainly between managers or decision makers within the company. It is also common that Tier 1 suppliers present their systems to the OEM's during the winter testing period.

At the proving ground it is necessary for all actors, OEMs, Tier 1 suppliers and service providers, to collaborate, coordinate and synchronise the efforts so that the tests perform well. Time is a constraint that is crucial, and has an effect on all actors' activities. 
The tests are performed in 'time slots', that is, a specific system, feature, component, behaviour etcetera are tested one at the time during the test period. Time to market is of vital importance in the automotive industry; thus, finding supportive development processes is a concern. The OEMs are experiencing the pressure from the approach of shortening lead times in early development. One OEM expresses his view on how this have an effect on the testing activities: "Shorter project times results in winter tests not making it to the finish line...". Further, lowering cost, in particular development costs, is another aspect that is in focus in the automotive industry. On the testing site this has resulted in fewer available prototype cars, thus the number of cars to use in the tests is found as a bottleneck. In turn, few prototype cars put higher emphasis on effective testing methods and to use the time at the proving ground more efficiently.

When discussing remote technologies with Tier 1 suppliers, one of them favoured logged data at the expense of real-time data. He said: "Real-time data is not as important as the possibility to replay the last run from the logged data in the car". Another supplier explained why: "We would like to see the last run we did and compare multiple runs with each other". In addition, another Tier 1 supplier highlighted the fact that they were a relative small group at the company, 25 persons, and that the use and investment in remote technology did not make sense for them. They could all travel and meet up at the proving ground if needed; otherwise they could use telephone conference calls for major issues.

Repeatability of the tests is a concern that OEMs experience as important. "After several runs on the same track to get uniformity we start our test. After the test, we do the next test on a new area". The service provider contributes to repeatability in the tests by providing similar ice track conditions. Ice and snow are tricky and change due to, for example, changes in temperature. Providing large areas to move around the test cars are therefore necessary. One engineer at a service provider explained that: "As soon as you have driven three times on packed snow you have to move to get the repeatability".

The service providers have observed that OEMs perceive time as a constraint. Thus, the service providers have considerations for how they can contribute to effectiveness and efficiency in the testing activities. One of them said: "The projects are getting shorter, so we need technology and equipment that are fast and easy to mount and to use". This view is supported by a OEM manager: "the bottlenecks are the number of prototype cars available due to development costs, and the state-of-the-art measurement methods needed to find problems with the product". Thus, it seems to be a lack in easy and smoothly mounted test equipment for the automotive test, and also a need for standardised off the shelf measurement methods.

Moreover, the service providers often present new car systems, e.g., ABS, ESP, TCS and ARP at the proving grounds. These demonstrations are performed between different companies, but mainly between managers or decision makers within a company. When discussing the presentation event with a test engineer, see Exhibit 1, it was concluded that a supporting technology for visualising the effectiveness of the new systems could be helpful, both before the tests and during the test when the managers and decision makers follow along in the cars.

A test engineer at the service provider runs tests and is part of the application team, i.e., those responsible of the test of systems and embedded software using testing equipments. A typical day for a test engineer at the service provider is described in Exhibit 2, and a presentation day is described in Exhibit 1. 
Exhibit 1 A typical presentation day for a test engineer

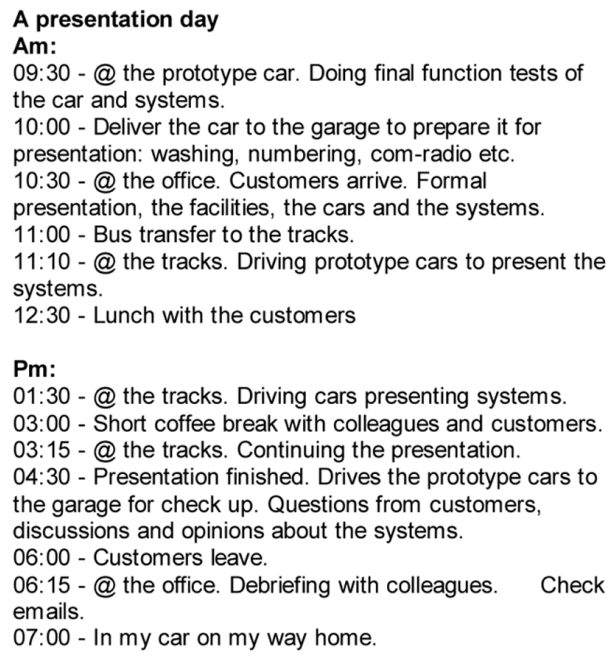

Exhibit 2 A typical day for a test engineer

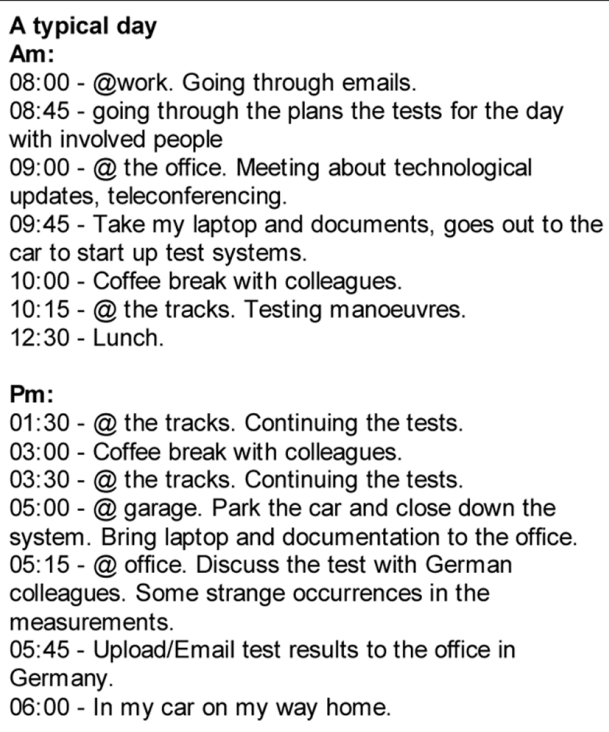

At the proving ground there is also a test manager who is head of the application team and responsible for the coordination and performance of the tests. A typical day at the proving ground for a test manager is described in Exhibit 3.

Interpreting some of the activities that takes place in the Exhibits 1-3 can highlight that the time available for performing the tests as such is limited. Therefore, it makes sense that the respondents say that test equipment must be quick and easy to install in the vehicle. If the test lasts for a day, and especially if the equipment has to be moved between prototype cars during that day the situation is much worse. 
Also, interpreting the activities in Exhibit 3 some interesting issues occur:

- The test manager likes to improve the behaviour of the engine feel while starting on different surfaces using the Anti-Slip System (ASR). He is not happy with the behaviour of the car, but cannot do more until he can understand the embedded software of the ASR. One solution can be a technology that would help in pinpointing the disturbing response of the ASR system in the vehicle.

- To understand the embedded software of the ASR, the test manager needs help of an expert, to get this he has to wait until tomorrow for the expert to reply. One solution that would prevent a time delay is access to the expert during the day when the tests are performed. They could have communicated about the disturbing response in the ASR and the expert could have helped the test manager to understand the embedded software. Not only could they have solved that problem quicker, but also, they could have jointly solved the problem with the car behaviour. The ability to replay the test drive could have supported a deeper joint analysis.

- The weather information is important for being able to plan the test and be prepared for changes in the tests during the following day. So having access to good weather forecasts is of importance.

Exhibit 3 Typical day for a test manager

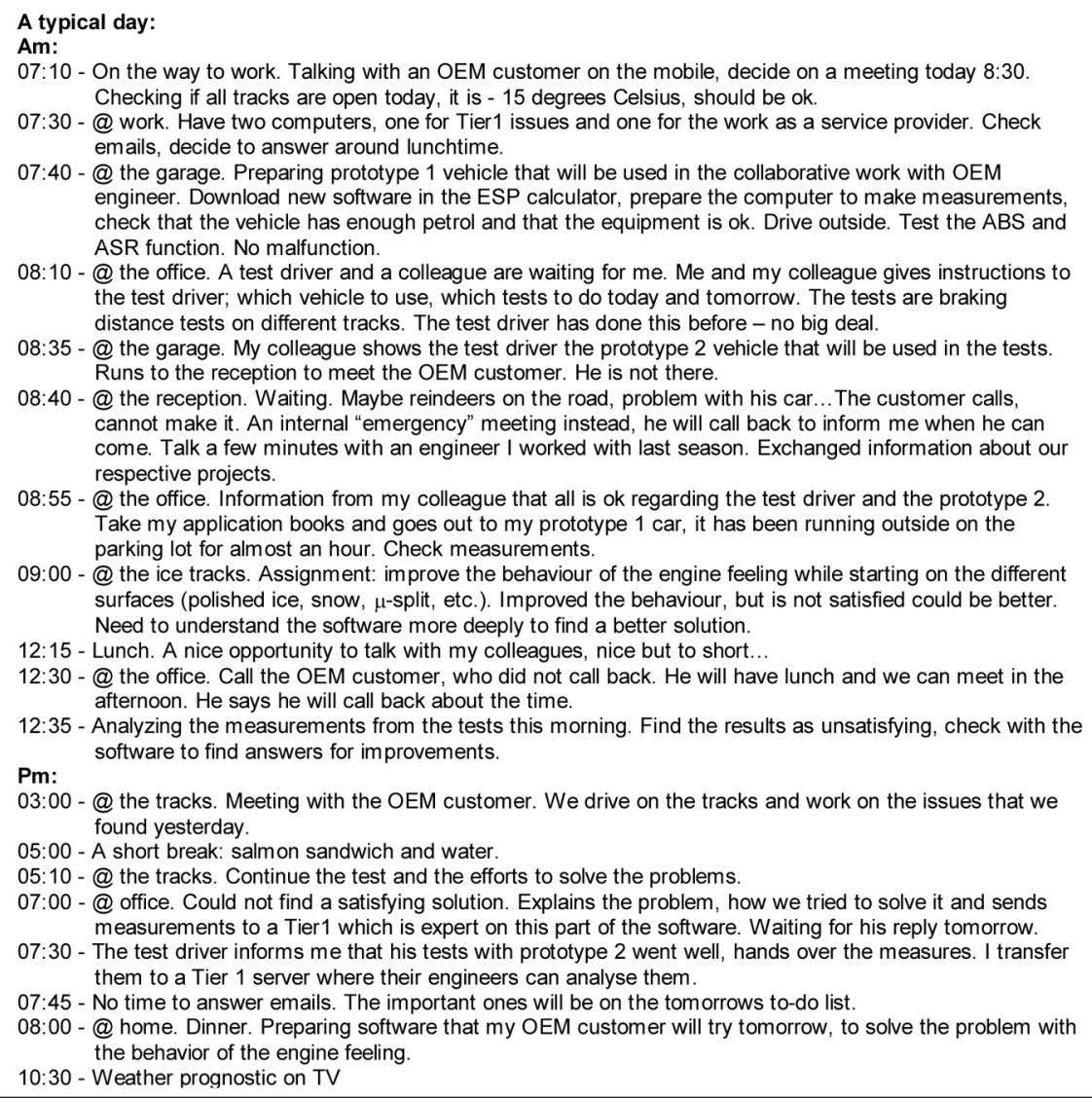

08:55 - @ the office. Information from my colleague that all is ok regarding the test driver and the prototype 2. Take my application books and goes out to my prototype $1 \mathrm{car}$, it has been running outside on the parking lot for almost an hour. Check measurements.

09:00 - @ the ice tracks. Assignment: improve the behaviour of the engine feeling while starting on the different surfaces (polished ice, snow, $\mu$-split, etc.). Improved the behaviour, but is not satisfied could be better. Need to understand the software more deeply to find a better solution.

12:15 - Lunch. A nice opportunity to talk with my colleagues, nice but to short.

12:30 - @ the office. Call the OEM customer, who did not call back. He will have lunch and we can meet in the afternoon. He says he will call back about the time.

12:35 - Analyzing the measurements from the tests this morning. Find the results as unsatisfying, check with the Pm: software to find answers for improvements.

03:00 - @ the tracks. Meeting with the OEM customer. We drive on the tracks and work on the issues that we found yesterday.

05:00 - A short break: salmon sandwich and water.

05:10 - @ the tracks. Continue the test and the efforts to solve the problems.

07:00 - @ office. Could not find a satisfying solution. Explains the problem, how we tried to solve it and sends measurements to a Tier 1 which is expert on this part of the software. Waiting for his reply tomorrow.

07:30 - The test driver informs me that his tests with prototype 2 went well, hands over the measures. I transfer them to a Tier 1 server where their engineers can analyse them.

07:45 - No time to answer emails. The important ones will be on the tomorrows to-do list.

08:00 - @ home. Dinner. Preparing software that my OEM customer will try tomorrow, to solve the problem with the behavior of the engine feeling.

10:30 - Weather prognostic on TV 
A proving ground manager is responsible for the activities at the test site, and also the person that is marketing the testing services. A typical day at the proving ground for the proving ground manager is described in Exhibit 4.

Exhibit 4 Typical day, proving ground manager

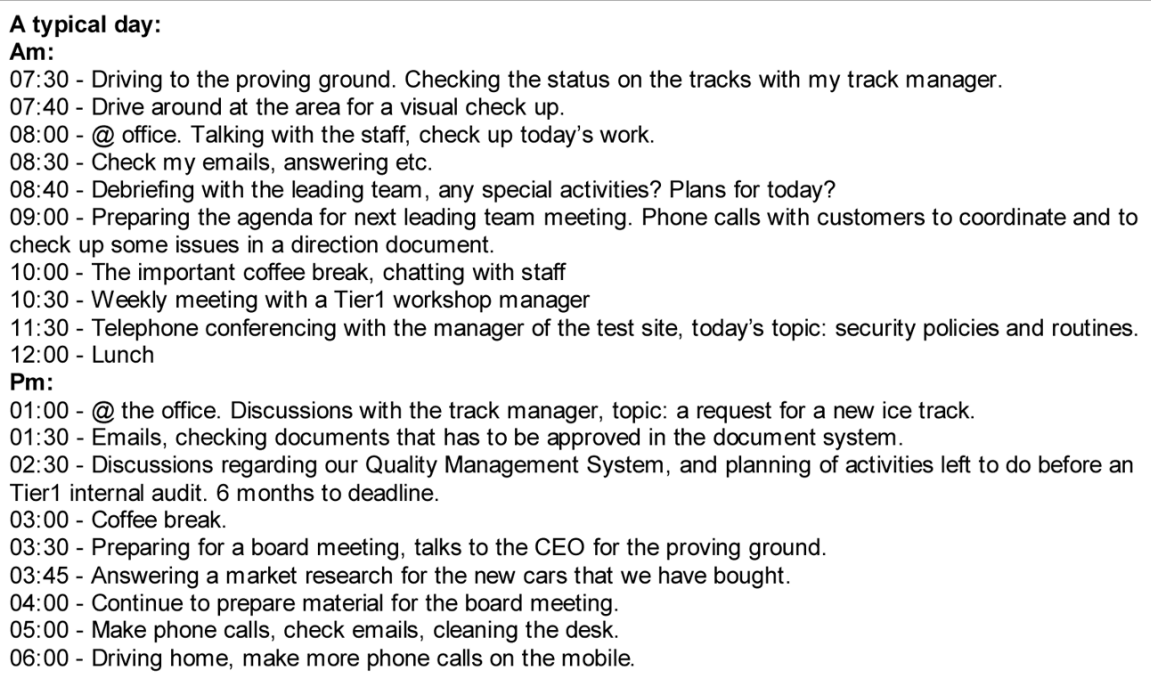

In the descriptions of 'typical days' above the importance of coffee breaks can be seen. This might be part of a Swedish culture and gives an opportunity to talk about everything else but the works. But, the respondents in this study have emphasised that these coffee breaks also are important to share knowledge, coordinate work and build on each others' experiences. The service providers commonly also suggest and coordinate accommodation, travels, tourism etcetera with other service companies.

\section{Remote Test Management}

The idea of RTM, is based on previous studies in automotive winter testing. One early study of remote technologies concerns climate control (Törlind, 2004) and this has been used in a follow up study to evaluate the use of remote technologies. Some concerns were highlighted in the latter study; for example, the security of transmitting data wireless between and from the vehicles (Hardell, 2007). Yet, the test engineers did express that remote technologies probably will bring about more possibilities than risks. For instance, they can run comparative tests, data from all cars in the test group can be monitored and experts can from distance communicate and give feedback to the running cars in the test group.

It can be seen from related and recent research that the interest in sending data to and from the vehicles are of interest for the automotive industry, especially for updating Electronic Control Unit (ECU) with upgraded software or remotely diagnose the systems (Larsson et al., 2008). Also, a Data Based Diagnostic approach for fleet management diagnostics and an approach called Model Based Diagnostics have been presented (Byttner et al., 2007). In the reports of these studies it becomes evident that the view of 
remote technologies in the vehicle industry, and testing in general, has changed. The fact that a local company providing the use of such technologies was formed in 2007 supports this argument. ${ }^{3}$ The company set up was initialised in relation to a research project (Törlind, 2004; Johanson and Karlsson, 2006). Together with other similar companies, e.g., mm-lab, ${ }^{4}$ they provide fleet management solutions to the test industry. The business idea for these companies is to provide advance tracking functions and measurement data transfers, where global positioning and measurement data is mission critical information. In a pervious study, the demonstration and testing of remote technologies, a car manufacturer concluded that these types of technologies can help them save $€ 500,000$ each winter (Törlind, 2004). Also, later studies have indicated that fleet management and remote technologies are interesting for the automotive industry (Nybacka, 2009).

The RTM is developed as a demonstrator within a research project connected to the study in this paper. RTM consists of a number of modules, namely:

- vehicle dynamics

- vibration/noise

- exhaust measurement

- temperature and humidity measurements

- audio/video communication

- real-time analysis of measurement data.

An embedded wireless enabled sensor node called Mulle (Johansson et al., 2004) is used in RTM to easily connect different sensors which are used for analysing the vehicle and its environment. The Mulle sensor nodes make it easy to add or subtract different modules to create a framework suitable for a specific test. Thus, this will make the mounting of equipment on the prototype cars faster and easier. Mulle utilises standard wireless protocols and profiles for communication. This enables interoperability with standard consumer devices such as smart phones, laptops, or palm handhelds. To reduce installation time, Mulle supports zero-configuration networking, i.e., it advertises its own functions and discovers other devices and their functions. This feature enables Mulle to automatically install itself, and, also, it alerts about faulty sensors that can be replaced during a running test session. Mulle has low power consumption, which allows test sessions to last for several days without recharging batteries. In Figure 3, example of different Mulle sensors are presented, the numbers in Figure 3 represent:

1 Temperature sensors, measuring inside temperature

2 Microclimate sensors, measuring outside temperature and humidity

3 Acceleration sensors, measuring road input

4 Exhaust sensors, measuring exhaust values from a portable measuring equipment

5 Central unit managing all Mulle communication and connected to an 6 Degrees of Freedom (DOF) Inertial Measurement Unit (IMU) sensor

6 CAN-bus interface gathering relevant Controller-area Network (CAN) data such as wheel speed, steering angle. 
Figure 3 Mulle units connected together in a network of wireless technologies (see online version for colours)

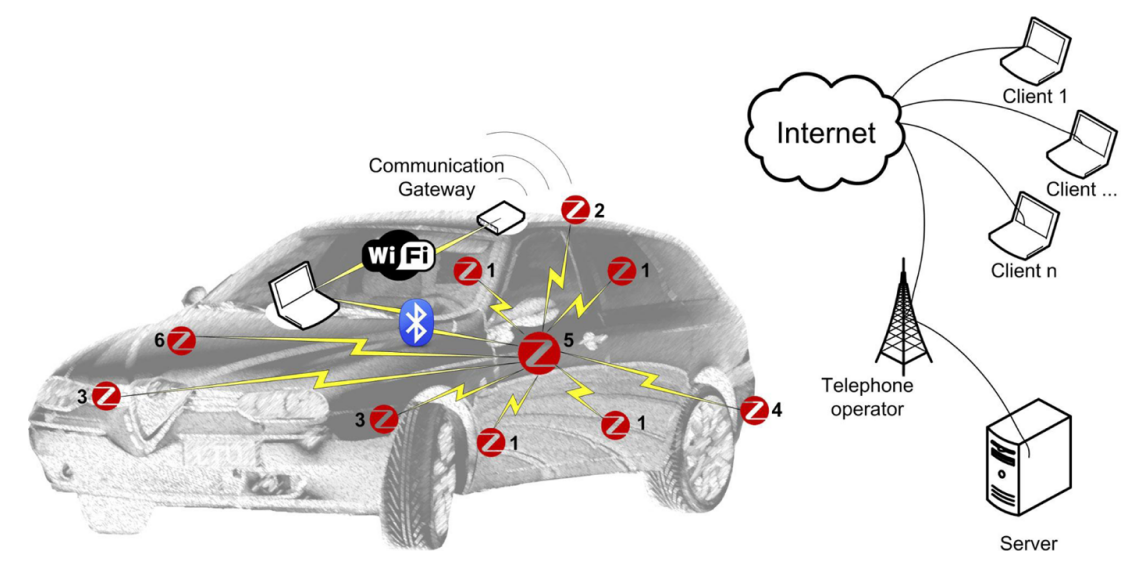

The central unit communicates via Bluetooth with an in-vehicle portable computer (symbolised by the laptop on the bonnet in Figure 3) and via WLAN with the on-board communication gateway (symbolised by the device on the roof in Figure 3). The communication gateway sends the data to a database server for storing and presentation of environment data and vehicle specific data, shown on the right side in Figure 3. Different clients can view the data and communicate with the vehicle from different locations, which have access to the internet, such as described in Nybacka et al. (2006).

\section{Discussing service innovation}

The service providers continuously develop the services at the proving ground. They are looking for ways to provide better services; for example, safety on the test tracks, in time, correct and relevant information about the weather conditions. Though, it can be argued that there is a focus on the more visible facilities; for example, related to the ice and land tracks. And, in addition, a focus on services required to make people from the automotive industry comfortable even though they are away from home; for example tourism and adventures. These are important. Yet, the advancement of automotive systems and more complex cars has 'gradually' made the testing activities more dependent on technologies. In this context, the technological services provided at the proving ground seem to be more invisible. This, we will argue, can relate to a perspective of technologies as the expertise area of OEM and Tier 1. In turn, such view makes it difficult to proactively take the next step in providing technological support. Though, in our studies we have found that the service providers already act as a competent and trusted partner in the testing activities.

In our empirical studies we have found that an upcoming challenge for OEM and Tier 1 is the issue of developing well-defined methods to be able to standardise tests. This might be one opportunity for service providers to provide new services. In this paper, we argue that RTM can be part of such service innovation. RTM, or similar remote technologies and management systems, have the potential to become a platform for new 
services since they enable, e.g., endurance tests that can be followed from other sites. This also makes it possible for service providers to offer an extended testing season.

The quick and easy installation that the, in RTM included, Mulle sensors offers can be an important part of innovative services. A benefit of Mulle sensors is that they reduce not only installation time, but also do not require extensive configuration. The wireless properties of Mulle play an important role for making the customers agree on having an additional system onboard the prototype car, but also for providing improved services. For instance, RTM can increase the safety when driving on the test tracks and on public roads. This is due to the included GPS technology of the fleet management platform. This provide for 'clever' use of information about the environment that the vehicles are driving in. When driving on the tracks RTM can alert the driver of e.g., other prototype cars on the tracks. But, also when driving on public roads, RTM can forewarn for reindeers (they are common on the roads), etc. From the perspective of the test manager, RTM and its fleet management platform offers coordination of the testing activities and the prototype cars on the tracks.

Further, RTM mounted cars that are driving on test tracks and public roads can possibly offer better weather forecasting. Temperature and humidity are thereby constantly logged, providing for more exact knowledge about specific microclimates and where they are located, e.g., thermal inversion spots. In addition, the state estimation algorithms of RTM can estimate the friction on the driving surface (roads or tracks). The test manager can use this information to monitor the test track's properties and know when the tracks have to be prepared again and thus gain statistical data that can be used for planning the following season. Information from the state estimation can be used when planning test cases requiring a certain percentage of low/high- $\mu$, split- $\mu$, or $\mu$-spots, e.g., stress tests of ESP, ABS, and TCS systems. Further, information on the roads' roughness can also be used as explained above. Meaning, to not only planning to run the cars on a minimum of $70 \%$ gravel roads, but also actually designing a test route out of a wanted Power Spectral Density (PSD) profile (González et al., 2008). Such information about the roads can be stored for each year and thus build up a knowledge base for the service providers, not only about the winter climate, but also for summer.

Regarding the performance and quality of tests, RTM can act as a basis for a framework that supports the education of test drivers and test engineers, thus permitting test drivers to be trained according to a certain driver profile by following a logged master manoeuvre or route. OEM and Tier 1 can set up a certain 'driver profile' in advance and the service providers can support them with trained drivers following these routes. The idea of driver profiles could also provide the service to educate public people in eco-driving.

The use of 3D visualisation technology makes it possible to see the vehicle and its behaviour in real-time, if wanted, or as a replay of a certain test. This is doable since the last run can be replayed from logged data in the 3D environment. Also, the 3D visualisation in the RTM framework admits the possibility of setting up a clipping plane trough the 3D model, thus allowing the user to view the inside of the car and the presented data, e.g., temperature or sound data viewed on the clipping plain with colours representing high or low values. The capability to save all sorts of time- and geo-stamped data will significantly enhance the data analysis and tracing of errors. Moreover, RTM can be helpful in the system demonstrations performed by the service providers. This makes it possible to present the systems performance before, during and after test-drives, as is discussed in Exhibit 1, thus making it easier to understand the systems. 
Further, engaging experts from all over the world in the running tests could be done. Hence, by being able to have an expert on stand-by, as exemplified in Exhibit 3, makes problem solving less time consuming.

The RTM framework can easily be extended. For instance, the addition of a portable exhaust measurement system allows for even more detailed analyses, or adding a CAN-bus analyser permits the acquisition of wheel speeds and steering angles. Further, the RTM system enables service providers to run benchmark tests with other brands for their customers, which might prove to be a stepping stone to extended services by showing their customers what service providers and the RTM system can do.

Basically, RTM offers several possibilities to service innovations. The technological solutions do exist today, yet as a whole it is still in research mode.

\section{Conclusions}

In this paper, the purpose was to discuss how technologies support service innovation. A RTM system, RTM has been outlined and served as a basis for those discussions. The interest and need for the service providers at proving grounds to extend their service provision have been identified in the study presented here. Yet, to profit from an investment in remote technology it is suggested that the benefits are understood (Carlson, 2006). The benefits, as far as can be concluded within this study, are:

- working closer to the OEM and Tier 1 suppliers and taking more active part in the tests give the service providers a potential to build up a unique knowledge base

- the technology leap provided by RTM can prove to be crucial for extending the test season to encompass summer tests

- the technology of RTM has the potential to provide new services or extending the ones that exist. It is even possible to find new services off-season to the public.

Also, the concept of PSS has framed this study to trigger a shift in how the services are viewed by the service provider. The discussion in this paper shows that going from a view of services at the proving ground as product-oriented (Williams, 2007), e.g., providing access to tracks and the facilities, to a more result-oriented (Williams, 2007) view, e.g., providing test performance and quality, makes several perspectives of services visible. In all, the PSS vision makes manufacturing companies reconsider their products in new ways. But, it can also inspire service providers to reconsider how to progress new services. But, one condition, and also an implication, seems to be that they have to take the first step.

Finally, RTM as a framework is a research demonstrator developed to trigger supportive remote methods in the testing industry to emerge. It should be noted that remote technologies was met with scepticism in 2005 (when this research project started), but over the years the automotive industry in general has become more confident about such an approach. Yet, further research on the RTM is needed before going into business, and also validation of the approach is of utmost concern. To improve implementation, there are some aspects that still have to be considered in future studies, for example the security of data transmission and handling. The idea of gathering mean value data is under consideration. This means that the service providers can run benchmark tests of cold starts with, e.g., exhaust measurements or temperature measurements. 
The implications of this approach will be followed up within this research project. Further, there is a constant need of running demonstration projects to show the effectiveness in this kind of technologies. Not only does the testing actors' point of view need to be considered, but also the IT departments' view. All new technologies have to be certified before implementation. The issue of updating/maintaining a RTM platform is another concern for the future. Further, there are different preferences for following tests at a distance but in real-time or being there and be able to replay. These are a few things that we have not considered in this paper, though the potential for RTM to serve as a technological platform to support co-production of new services has been outlined.

\section{Acknowledgements}

The time and efforts given by the respondents and informants of the work are deeply acknowledged. Also, funding from the Centre for Automotive Systems Technologies and Testing ${ }^{5}$ through Norrbottens Forskningsråd and Luleå University of Technology, as well as the European Regional Development Fund, through Tillväxtverket and project $\mathrm{I} 2$, is acknowledged.

\section{References}

Bovik, C. (2004) Customer-Perceived Value in Business Relationships, Doctoral Thesis, Division for Business and Economics, Department of Business Administration, Karlstad University, Sweden, p.44.

Byttner, S., Rögnvaldsson, T. and Svensson, M. (2007) Modeling for Vehicle Fleet Remote Diagnostics, SAE Technical Paper 2007-01-4154.

Carlson, J.R. (2006) Location, Diagnostics, and Commercial Transactions - Content Services for Business, SAE Technical Paper: 2006-21-0072.

Charter, M., Adams, G. and Clark, T. (2006) 'Need area 2: information and communication technologies', in Tukker, A. and Tischner, U. (Eds.): New Business for Old Europe: Product-Service Development, Competitiveness and Sustainability, pp.198-226.

Edvardsson, B., Johnson, M.D., Gustafsson, A. and Strandvik, T. (2000) 'The effects of satisfaction and loyalty on profits and growth: products versus services', Total Quality Management, Vol. 11, No. 7, pp.917-927.

Ghaye, T., Melander-Wikman, A., Kisare, M., Chambers, P., Bergmark, U., Kostenius, C. and Lillyman, S. (2008) 'Participatory and Appreciative Action and Reflection (PAAR) democratizing reflective practices', Reflective Practice, Vol. 9, No. 4, pp.361-397.

Gonzáles, A., O’brien, E.J., Li, Y-Y. and Cashell, K. (2008) 'The use of vehicle acceleration measurement to estimate road roughness', Journal of Vehicle System Dynamics, Vol. 46, No. 6, pp.485-501.

Grimm, K. (2003) 'Software technology in an automotive company - major challenges', Proceedings of the 25th International Conference on Software Engineering, ICSE'03, pp.498-504.

Grönroos, C. (2000) Service Management and Marketing: A Customer Relationship Management Approach, Wiley, Chichester.

Gummesson, E. (2002) Total Relationship Marketing - Marketing Management, Relationship Strategy and CRM Approaches for the Network Economy, 2nd ed., Butterworth Heinemann, Cornwall. 
Hardell, K. (2007) Samarbetsrapport: Hur kan Tjintokk samarbeta med LTU och UMU?, Umeå Universiy, Umeå.

Johanson, M. and Karlsson, L. (2006) 'Framework for distributed collaborative automotive testing', 4th Workshop on Challenges in Collaborative Engineering, Prague, Czech Republic.

Johansson, J., Völker, M., Eliasson, J., Östmark, Å., Lindgren, P. and Delsing, J. (2004) MULLE: A Minimal Sensor Networking Device - Implementation and Manufacturing Challenges, IMAPS Nordic, Helsingör, Denmark, pp.265-271.

Krüger, I.H., Ahluwalia, J., Gupta, D., Mathew, R., Moorthy, P., Phillips, W. and Rittmann, S. (2004) 'Towards a process and tool-chain for service-oriented automotive software engineering', Proceedings of the ICSE 2004 Workshop on Software Engineering in Automotive Systems (SEAS).

Larsson, A. (2005) Engineering Know-Who: Why Social Connectedness Matters to Global Design Teams, Doctoral Thesis, Luleå University of Technology, Sweden, p.19.

Larsson, U.E., Nilsson, D.K. and Jonsson, E. (2008) 'An approach to specification-based attack detection for in-vehicle networks', IEEE Intelligent Vehicles Symposium, Eindhoven, Netherlands.

Mont, O.K. (2002) 'Clarifying the concept of production service system', Journal of Cleaner Production, Vol. 10, pp.237-245.

Normann, R. (2001) Reframing Business: When the Map Changes the Landscape, John Wiley \& Sons Ltd., UK.

Nybacka, M. (2009) Opportunities in Automotive Winter Testing, ASME IDETC/CIE, San Diego, USA.

Nybacka, M., Karlsson, T. and Larsson, T. (2006) 'Vehicle validation visualization', Virtual Concept 2006, Playa Del Carmen, Mexico.

Proposed FMVSS No. 126 (2006) Electronic Stability Control Systems, Preliminary Regulatory Impact Analysis, US Department of Transportation, National Highway Traffic Safety Administrations.

Sandberg, M., Boart, P. and Larsson, T. (2005) 'Functional product life-cycle simulation model for cost estimation in conceptual design of jet engine components', Concurrent Engineering, Research and Applications, Vol. 13, No. 4. pp.331-342.

Schäuffele, J. and Zurawaka, T. (2005) Automotive Software Engineering: Principles, Processes, Methods, and Tools, SAE International, Warrendale, USA.

Törlind, P. (2004) 'A collaborative framework for distributed winter testing', eChallenges e-2004, Vienna, Austria.

Williams, A. (2007) 'Product service systems in the automobile industry: contributing to system innovation?', Journal of cleaner Production, Vol. 15, pp.1093-1103.

\section{Notes}

${ }^{1}$ www.arcticfalls.se

${ }^{2}$ www.spga.se

${ }^{3}$ www.rajdsystech.se

${ }^{4}$ www.mmlab.de

${ }^{5}$ www.ltu.se/castt
} 